\title{
LA IMAGEN DEL CUIDADO DE ENFERMERÍA Y EL CORONAVIRUS (COVID 19)
}

\author{
The image of nursing care and the coronavirus (COVID 19)
}

\section{Dra. Isabel Natividad Urure Velazco ${ }^{1}$}

\author{
${ }_{1}^{1}$ Profesor principal de la Facultad de Enfermería, Universidad Nacional San Luis Gonzaga. Ica, Perú. Editora en Jefe de la Revista \\ Científica Enfermería a la Vanguardia (REVAN) Ica, Perú.
}

En tiempos actuales enfrentamos momentos, difíciles de una pandemia a nivel mundial, ocasionada por un virus denominada Coronavirus (COVID 19)"considerada como pandemia por la Organización Mundial de la Salud (OMS), dejando miles de muerte e infectados en todo el mundo" (1).En este contexto suman y aúnan esfuerzo el personal sanitario de salud (enfermeras, médicos, personal técnico de enfermería entre otros etc...), para atender a los pacientes infectados por este virus desconocido, agresivo y mortal convirtiéndose en héroes guerreros en la primera línea de batalla contra el Coronavirus (COVID 19),que se exponen a ser contagiados para salvar la vida de los enfermos en el mundo y en nuestro país. Donde la labor de la enfermera/o se refleja en el cuidado, término que es y será inherente al profesional de enfermería, desde épocas remotas lo destaca la primera teórica de enfermería Florence Nightingale quien señala...que enfermeras son "personas capacitadas en el cuidado de los enfermos" (2). Asimismo, la profesión de enfermería desde Nightingale durante la Guerra de Crimea ((1853-1856) comienza a cambiar la imagen que tenía el público de enfermería. "A menudo se distingue a Nightingale como la primera teórica que elevo el nivel de enfermería por medio de la educación"(2), con sus escritos y en la práctica diaria al cuidado a los soldados, inicio la mejora de las condiciones higiénicas y sanitarias"(3), teoría que se centra en el entorno saludable ( aire, puro, agua potable, eliminación de aguas residuales, higiene y luz),,estos se considera tan indispensables en la actualidad como hace 150 años, en la cual la higiene como concepto es uno de los elementos esencial de la teoría del entorno de Nightingale, resaltando dentro de este elemento el lavado de manos con frecuencia, estimado hoy esta norma aplicada antiguamente como una de las medidas preventivas prioritarias para eliminar el virus del coronavirus (COVID 19), y romper la cadena de transmisión, considerada por la OMS como "la enfermedad infecciosa causada por el coronavirus que se ha descubierto más recientemente. Tanto el nuevo como la enfermedad eran desconocidas antes de que estallara el brote en Wuhan (China) en Diciembre 2019" (4). "Estamos frente a un virus grande, pesado que tiene proteínas con azúcar y esto lo hace pesado y cae a una distancia de 1,20 a 1,50 metros, entrando por las mucosas (ojos, nariz, boca)" (5). Siendo el contagio de persona a persona, de ahí la importancia de seguir las medidas higiénicas del lavado de manos con frecuencia, el uso de la mascarilla, que conjuntamente con el aislamiento social, cuarentena, contribuye a que el virus no se expanda "quedándose en casa" esta frase en nuestro país (Perú) fue etiquetado en programas radiales, televisivos, teléfonos, página Web, de manera de efecto multiplicador de llegar a la población ,con el objetivo de aplanar la curva exponencial de ascenso del virus (evitando el contagio en el periodo de incubación),dando un promedio de 12 días, periodo en el cual la persona infectada desarrolla anticuerpos contra el COVID 19.En estas circunstancias de aislamiento social, se ha podido observar el comportamiento de la sociedad, mostrando afecto a los protagonistas principales, por la labor desplegada, desarrollando un espíritu de solidaridad, a tener paciencia ,la creatividad etc. Por otro lado se ha podido vivenciar, los beneficios de la naturaleza ha descansado, reduciéndose la contaminación ambiental y sonora, los animales recuperaron su espacio, aflorando la presencia de especies no visualizadas antes en mares, ríos, lagos y en el ambiente .En tanto situaciones como esta crisis, que atravesamos a nivel mundial hace que la población visibilice en la real dimensión la importancia de la imagen del cuidado 
de Enfermería al asistir a pacientes infectados con (COVID 19), demostrando dedicación, abnegación del cuidado holístico, en forma continua, permanente en el contacto directo, luchando contra el enemigo invisible que no se conocía antes, que es mortal y agresivo, sujeto a contagiarse y esta a su vez a su entorno familiar porque la "Enfermería es cuidado de salud y cuidado de la enfermedad, prevención, promoción de la salud y rehabilitación. Asimismo, es cuidado comunitario, casero, institucional, de salud mental y de manera creciente, autocuidado. La enfermería está presente desde el principio hasta el final de la vida...(2)

Finalizo con la reflexión La unión espiritual, solidaridad, cambio de actitudes y disciplina de la comunidad, es la fuerza que necesitamos para combatir este virus invisible que nos ha reunido a la familia en casa, pero con un distanciamiento social.

\section{REFERENCIAS BIBLIOGRÁFICAS.}

1. El Comercio. Diario Peruano. Lima, Perú. 25 de Marzo 2020

2. Kozier B, Erb GI, Bufalino P. Fundamentos de Enfermería. México: Ed. Interamericana; 2001: Capitulo 1, p.4.

3. Potter P, Perry A. Fundamentos de Enfermería. 6a ed. Volumen I. Madrid, España; Ed. Elsevier; 2007: p. 95.

4. Organización Mundial de la Salud (OMS). Preguntas y respuestas sobre la enfermedad por coronavirus (COVID-19.(Internet).2020( Citado el 22 de Marzo 2020). Disponible en: https://www.who.int/es/emergencies/diseases/novel

5. Miroli A. Coronavirus: Consejos (Internet). Argentina (Citado 23 el de Marzo 2020) Disponible en: https://www.youtube.com/watch?v=wJOFSoS8Qmw 